\title{
Differential effect of body mass index on pediatric heart transplant outcomes based on diagnosis
}

Godown J, Donohue JE, Yu S, Friedland-Little JM, Gajarski RJ, Schumacher KR. (2014) Differential effect of body mass index on pediatric heart transplant outcomes based on diagnosis. Pediatr Transplant, 18: 771-776. DOI: 10.1111/petr.12352.

Abstract: The impact of nutritional status on HTx waitlist mortality in children is unknown, and there are conflicting data regarding the role of nutrition in post-HTx survival. This study examined the influence of nutrition on waitlist and post-HTx outcomes in children. Children 2-18 yr listed for HTx from 1997 to 2011 were identified from the OPTN database and stratified by BMI percentile. Multivariable logistic regression evaluated the influence of BMI on waitlist mortality. Cox proportional hazard regression assessed the impact of BMI on postHTx mortality. When all 2712 patients were analyzed, BMI did not impact waitlist, one-, or five-yr mortality. However, when stratified by diagnosis, $\mathrm{BMI}>95 \%$ (AOR 1.96; 95\% CI 1.24, 3.09) and $\mathrm{BMI}<1 \%$ (AOR 2.17; 95\% CI 1.28, 3.68) were independent risk factors for waitlist mortality in patients with CM. BMI did not impact waitlist mortality in CHD and did not impact post-HTx outcomes, regardless of diagnosis. BMI $>95 \%$ and $\mathrm{BMI}<1 \%$ are independent risk factors for waitlist mortality in patients with $\mathrm{CM}$, but not CHD. This suggests differing risk factors based on disease etiology, and an individualized approach to risk assessment based on diagnosis may be warranted.

\author{
Justin Godown', Janet E. Donohue'2, \\ Sunkyung $\mathrm{Yu}^{2}$, Joshua M. Friedland- \\ Little $^{2}$, Robert J. Gajarski ${ }^{2}$ and \\ Kurt R. Schumacher ${ }^{2}$ \\ ${ }^{1}$ Division of Pediatric Cardiology, Monroe Carell Jr. \\ Children's Hospital at Vanderbilt, Nashville, TN, \\ USA, ${ }^{2}$ Division of Pediatric Cardiology, Department \\ of Pediatrics, C.S. Mott Children's Hospital, \\ University of Michigan, Ann Arbor, MI, USA
}

Key words: heart transplantation - pediatrics body mass index - cardiomyopathy - congenital heart disease

Justin Godown, MD, 2200 Children's Way, Suite 5230, D0T, Nashville, TN 37232-9119, USA

Tel.: 6153227447

Fax: 6153222210

E-mail: justin.godown@vanderbilt.edu

Accepted for publication 1 August 2014
Nutritional status has recently been identified as an independent risk factor for waitlist mortality in infants awaiting HTx (1); however, it is unknown if pre-HTx nutrition impacts waitlist survival in older pediatric patients. Additionally, there are conflicting data regarding the impact of pre-HTx nutrition on post-HTx survival in pediatric patients (2-5), despite adult data indicating decreased survival in the setting of wasting or obesity $(6,7)$. Furthermore, recent studies have demonstrated that risk factors for non-survival following pediatric HTx differ based on heart disease etiology $(8,9)$, but nutrition was not rigorously studied in those analyses. This study aimed to assess (i) the impact of

\footnotetext{
Abbreviations: AHR, adjusted hazard ratio; AOR, adjusted odds ratio; BMI, body mass index; CHD, congenital heart disease; $\mathrm{CI}$, confidence interval; $\mathrm{CM}$, cardiomyopathy; ECMO, extracorporeal membrane oxygenation; HTx, heart transplant; IBW, ideal body weight; OPTN, Organ Procurement and Transplantation Network; Ref, reference category; VAD, ventricular assist device.
}

pre-HTx nutrition on waitlist and post-HTx outcomes in patients aged 2-18 yr and (ii) determine whether the risk conferred by suboptimal nutritional status differed based on pre-HTx diagnosis.

\section{Methods}

This is a retrospective cohort study utilizing the OPTN database.

\section{Patient selection and data collection}

The OPTN database was queried for all patients aged 2-18 yr listed for HTx in the United States between 1997 and 2011. BMI percentile was calculated at the time of listing for each patient, and nutritional groups were classified as follows: obese (BMI > 95\%), overweight (BMI 85-95\%), normal (BMI 5-85\%), underweight (BMI 1-5\%), and severely wasted $(\mathrm{BMI}<1 \%)$. Because exact ages are not available in the OPTN data, BMI percentiles were calculated at the half-year mark for each patient to minimize error. Patients were excluded from analysis if they underwent a prior transplant, underwent a non-orthotopic HTx, weight or height was missing, or if they failed to meet an outcome while on the waitlist (death or HTx). Also, to minimize error 
due to spurious values, patients were excluded if they had a decrease in height between listing and transplant of $>5 \mathrm{~cm}$, or a markedly abnormal BMI z-score $(>6$ or $<-6)$. Additional variables collected for analysis included gender, race, blood type, age at listing, status at listing (1A, 1B, or 2), diagnosis (CHD, CM, or other), waitlist time, ventilator use, ECMO requirement, VAD support, inotrope use, and infections requiring IV drug therapy within two wk of listing. Following analysis of the entire study cohort, the cohort was stratified into two groups by diagnosis (CM or CHD) and the analysis was repeated. Patients with a diagnosis of "other" were excluded when the cohort was stratified. The primary outcomes were (i) waitlist mortality, (ii) post-HTx mortality at one yr, and (iii) post-HTx mortality at five yr.

\section{Statistical methods}

Demographics and patient characteristics between survivors and non-survivors were compared using the chi-square test or Fisher's exact test for categorical variables and Wilcoxon rank sum test for continuous variables. Risk factors associated with waitlist mortality were assessed using logistic regression, and factors associated with one- and five-yr postHTx mortality were assessed using Cox proportional hazard models. Variables found to be significantly associated with waitlist or post-HTx mortality on univariate analysis $(\mathrm{p}<0.1)$ were adjusted for in the multivariable regression models to determine independent associations of pre-HTx nutrition with outcomes. All analyses were performed using SAS version 9.3 (SAS Institute Inc, Cary, NC, USA).

\section{Results}

Of 3031 patients listed for HTx during the study period, 2712 were included in the analysis. Of the patients excluded from analysis, $86(2.8 \%)$ were removed from the waitlist due to clinical deterioration. Nutritional status in this group was not significantly different compared with those who underwent HTx or who died on the waitlist $(\mathrm{p}=0.29$ from chi-square test). Baseline patient characteristics are shown in Table 1. At listing, $354(13 \%)$ patients were obese, $284(10 \%)$ were overweight, $1598(59 \%)$ were normal, $210(8 \%)$ were underweight, and $266(10 \%)$ were severely wasted. Of the patients included in the study, $2345(86 \%)$ survived to HTx, while $367(14 \%)$ died on the waitlist. When the entire study cohort was analyzed, nutrition at listing was not associated with waitlist mortality after adjusting for race, blood type, age at listing, status at listing, diagnosis, ventilator requirement, ECMO or VAD support, inotrope use, and nutritional status (Table 2). Of the patients who underwent HTx, 2129 (91\%) survived one yr and $1869(80 \%)$ survived five $\mathrm{yr}$ post-HTx. Nutritional status at listing had no impact on one- or five-yr post-HTx mortality after controlling for gender, race, diagnosis, age at listing, status at listing, and the need for ECMO support (Table 3).

There were 1662 patients $(61 \%)$ with a diagnosis of CM. Of these patients, $256(15 \%)$ were obese, $189(11 \%)$ were overweight, 944 (57\%) were normal, $122(7 \%)$ were underweight, and $151(9 \%)$ were severely wasted. A total of 1490 patients $(90 \%)$ with CM underwent HTx and 172 $(10 \%)$ died on the waitlist. Both obesity (AOR $1.96 ; 95 \%$ CI $1.24,3.09)$ and severe wasting (AOR 2.17; 95\% CI 1.28, 3.68) were independent risk factors for waitlist mortality in this group after adjusting for blood type, age at listing, status at listing, ventilator requirement, and ECMO or VAD support (Table 4). Of those who underwent HTx, 1387 (93\%) survived one yr and 1225 $(82 \%)$ survived five yr post-HTx. Nutrition was not a risk factor for one- or five-yr post-HTx mortality in this group when controlling for gender, race, diagnosis (dilated $\mathrm{CM}$, restrictive $\mathrm{CM}$, or hypertrophic $\mathrm{CM}$ ), and age at listing (Table 5). To exclude an era effect leading to these findings, a secondary analysis was performed using a more contemporary cohort (2002-2011). Severe wasting remained an independent risk factor for waitlist mortality with borderline significance $(\mathrm{p}=0.05)$; however, obesity no longer appeared as a significant risk factor for waitlist mortality.

Of $975(36 \%)$ patients with a diagnosis of CHD, 89 (9\%) were obese, $82(8 \%)$ were overweight, $608(62 \%)$ were normal, $85(9 \%)$ were underweight, and $111(11 \%)$ were severely wasted. A total of $800(82 \%)$ patients with CHD underwent HTx and 175 (18\%) died on the waitlist. In this group, nutritional status at listing was not associated with waitlist mortality after adjusting for race, blood type, status at listing, ventilator support, and inotrope use (Table 4). Of those who underwent HTx, $694(87 \%)$ survived to one yr and $600(75 \%)$ survived to five yr postHTx. Nutrition was not a risk factor for one- or five-yr post-HTx mortality when controlling for race and the need for ECMO support (Table 5).

Due to previous data suggesting that percent IBW may be a better predictor of morbidity and mortality following HTx in adult recipients than BMI (6), a secondary analysis was performed using IBW in lieu of BMI to stratify the cohort. This analysis resulted in similar findings that both obesity (IBW > 140\%) (AOR 2.03; 95\% CI 1.26, 3.29) and severe wasting (IBW < 80\%) (AOR 2.18; 95\% CI $1.25,3.80)$ were independent risk factors for waitlist mortality in patients with CM, but not CHD.

Additionally, it is known that some transplant centers view elevated BMI as a contraindication to HTx; however, there are little data to support this strategy. To address this, a secondary analysis was performed comparing waitlist and post-HTx outcomes of adolescent patients (ages 13-18) with $\mathrm{BMI}>35(\mathrm{~N}=34)$ to those with a $\mathrm{BMI}$ in the normal range $(18.5 \leq \mathrm{BMI}<25)$ $(\mathrm{N}=474)$. No difference in waitlist, one-, or five- 
Differential effect of BMI based on diagnosis

Table 1. Pre-transplant characteristics in patients aged 2-18 yr who underwent their first orthotopic HTx in the United States in the past $15 \mathrm{yr}(\mathrm{N}=2712)$

\begin{tabular}{|c|c|c|c|c|}
\hline \multirow[b]{2}{*}{ Characteristics } & \multirow[b]{2}{*}{ Overall } & \multicolumn{2}{|c|}{ Survival to transplant } & \multirow[b]{2}{*}{$p$-Value ${ }^{*}$} \\
\hline & & Yes (N = 2345) & No (N = 367) & \\
\hline Female sex & $1119(41.3)$ & $970(41.4)$ & $149(40.6)$ & 0.78 \\
\hline \multicolumn{5}{|l|}{ Race } \\
\hline Caucasian & $1510(55.7)$ & $1325(56.5)$ & $185(50.4)$ & \multirow[t]{4}{*}{0.16} \\
\hline African American & $610(22.5)$ & $516(22.0)$ & $94(25.6)$ & \\
\hline Hispanic & $395(14.6)$ & $334(14.2)$ & $61(16.6)$ & \\
\hline Other & $197(7.3)$ & $170(7.2)$ & $27(7.4)$ & \\
\hline \multicolumn{5}{|l|}{ Blood type } \\
\hline A & 992 (36.6) & $902(38.5)$ & $90(24.5)$ & \multirow[t]{4}{*}{$<0.0001$} \\
\hline B & $340(12.5)$ & $301(12.8)$ & $39(10.6)$ & \\
\hline 0 & $1272(46.9)$ & $1043(44.5)$ & $229(62.4)$ & \\
\hline$A B$ & $108(4.0)$ & $99(4.2)$ & $9(2.5)$ & \\
\hline Age at listing, yr & $11(6-15)$ & $12(6-15)$ & $10(4-15)$ & 0.01 \\
\hline$<4$ yr & $405(14.9)$ & $325(13.9)$ & $80(21.8)$ & 0.0004 \\
\hline $4-12$ yr & $1116(41.2)$ & $975(41.6)$ & $141(38.4)$ & \\
\hline 13-18 yr & 1191 (43.9) & $1045(44.6)$ & $146(39.8)$ & \\
\hline \multicolumn{5}{|l|}{ Status at listing } \\
\hline 1 or $1 \mathrm{~A}$ & $1,406(51.8)$ & $1,173(50.0)$ & $233(63.5)$ & \multirow[t]{4}{*}{$<0.0001$} \\
\hline $1 \mathrm{~B}$ & $370(13.6)$ & 327 (13.9) & $43(11.7)$ & \\
\hline 2 & $905(33.4)$ & $818(34.9)$ & $87(23.7)$ & \\
\hline Temporarily inactive or unknown & $31(1.1)$ & $27(1.2)$ & $4(1.1)$ & \\
\hline \multicolumn{5}{|l|}{ Diagnosis at listing } \\
\hline Cardiomyopathy & $1,662(61.3)$ & $1,490(63.5)$ & $172(46.9)$ & \multirow[t]{6}{*}{$<0.0001^{\dagger}$} \\
\hline Dilated cardiomyopathy & $1,364(50.3)$ & $1,214(51.8)$ & $150(40.9)$ & \\
\hline Restrictive cardiomyopathy & $225(8.3)$ & $209(8.9)$ & $16(4.4)$ & \\
\hline Hypertrophic cardiomyopathy & $73(2.7)$ & $67(2.9)$ & $6(1.6)$ & \\
\hline Congenital heart defect & $975(36.0)$ & $800(34.1)$ & $175(47.7)$ & \\
\hline Other & $75(2.8)$ & $55(2.3)$ & $20(5.4)$ & \\
\hline Waiting time, days & 40 (15-104) & $41(14-104)$ & $34(15-109)$ & 0.90 \\
\hline$<30$ days & $1,127(41.6)$ & $963(41.1)$ & $164(44.7)$ & \multirow[t]{2}{*}{0.19} \\
\hline$\geq 30$ days & $1,585(58.4)$ & $1,382(58.9)$ & $203(55.3)$ & \\
\hline Nutritional status at listing ${ }^{\ddagger}$ & & & & 0.16 \\
\hline Obese & $354(13.1)$ & $300(12.8)$ & $54(14.7)$ & $0.25^{\S}$ \\
\hline Overweight & $284(10.5)$ & $248(10.6)$ & $36(9.8)$ & $0.90^{\S}$ \\
\hline Normal & $1,598(58.9)$ & $1,391(59.3)$ & $207(56.4)$ & Ref \\
\hline Underweight & $210(7.7)$ & $187(8.0)$ & $23(6.3)$ & $0.41^{\S}$ \\
\hline Severely wasted & $266(9.8)$ & $219(9.3)$ & $47(12.8)$ & $0.04^{\S}$ \\
\hline Use of ventilator at listing & $313(11.5)$ & $212(9.0)$ & $101(27.5)$ & $<0.0001$ \\
\hline ECMO support at listing & $137(5.1)$ & $95(4.1)$ & $42(11.4)$ & $<0.0001$ \\
\hline Inotrope use at listing & $1,276(47.1)$ & $1,072(45.7)$ & $204(55.6)$ & 0.0004 \\
\hline Use of VAD at listing & $403(14.9)$ & $372(15.9)$ & $31(8.4)$ & 0.0002 \\
\hline $\begin{array}{l}\text { Infection requiring IV drug therapy } \\
\text { (within two wk of listing) }\end{array}$ & $126(4.6)$ & $106(4.5)$ & $20(5.4)$ & 0.01 \\
\hline
\end{tabular}

${ }^{*} \mathrm{p}$-Value from chi-square tests for categorical variables and Wilcoxon rank sum test for continuous variable on comparison of each characteristic between the patients who survived to transplant and those who did not.

${ }^{\dagger}$ Comparison was made between cardiomyopathy vs. congenital heart defect vs. others (p-value from chi-square test).

*Nutritional status defined as severely wasted if BMI < 1st percentile, underweight if BMl 1st-5th percentile, overweight if BMI 85-95th percentile, obese if $\mathrm{BMI}>$ 95th percentile, and normal if otherwise.

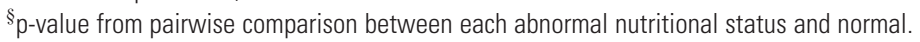

Data are presented as $\mathrm{N}(\%)$ for categorical variables and median (25-75th percentile) for continuous variables.

yr mortality was found between these groups; however, the analysis was limited by a small number of patients.

\section{Discussion}

This study provides new insight into the role that pre-HTx nutrition plays in waitlist and post-HTx survival in pediatric patients, and it demonstrates that pre-HTx diagnosis modifies the risk conferred by abnormal nutrition in children. The extremes of nutrition, either obesity or severe wasting, are associated with an increased risk of waitlist mortality in pediatric patients with $\mathrm{CM}$ awaiting HTx. Interestingly, this finding did not hold true in patients with a diagnosis of CHD, or 


\section{Godown et al.}

Table 2. Odds of non-survival to transplant based on pre-transplant nutrition in all patients aged 2-18 yr who underwent their first orthotopic HTx in the United States in the past $15 \mathrm{yr}(\mathrm{N}=2712)$

\begin{tabular}{|c|c|c|c|}
\hline Characteristics & $\mathrm{AOR}$ & $95 \% \mathrm{Cl}$ & $\mathrm{p}$-Value* \\
\hline Nutritional status at listing ${ }^{\dagger}$ & & & 0.33 \\
\hline Obese & 1.29 & $0.91,1.83$ & 0.15 \\
\hline Overweight & 1.00 & $0.67,1.49$ & 0.99 \\
\hline Normal & Ref & & \\
\hline Underweight & 0.81 & $0.50,1.30$ & 0.38 \\
\hline Severely wasted & 1.27 & $0.87,1.85$ & 0.22 \\
\hline
\end{tabular}

${ }^{*} \mathrm{p}$-Value from multivariable logistic regression.

†Nutritional status defined as severely wasted if $\mathrm{BMI}<1$ st percentile, underweight if BMI 1st-5th percentile, overweight if BMI 85-95th percentile, obese if $\mathrm{BMI}>$ 95th percentile, and normal if otherwise.

Table 3. Hazard ratios of non-survival at one and five yr post-transplant based on pre-transplant nutrition in all patients aged 2-18 yr who underwent their first orthotopic HTx in the United States in the past 15 yr $(\mathrm{N}=2345)$

\begin{tabular}{llll}
\hline Characteristics & AHR & $95 \% \mathrm{Cl}$ & p-Value $^{*}$ \\
\hline $\begin{array}{l}\text { One-yr non-survival based } \\
\text { on nutritional status at listing }\end{array}$ & & & 0.73 \\
$\quad$ Obese & 1.16 & $0.76,1.75$ & 0.49 \\
$\quad$ Overweight & 1.33 & $0.88,2.00$ & 0.18 \\
$\quad$ Rormal & 1.03 & $0.62,1.72$ & 0.90 \\
$\quad$ Underweight & 1.11 & $0.71,1.76$ & 0.64 \\
$\quad$ Severely wasted & & & 0.54 \\
$\begin{array}{l}\text { Five-yr non-survival based } \\
\text { on nutritional status at listing }\end{array}$ & & & \\
$\quad$ Obese & 1.10 & $0.84,1.46$ & 0.49 \\
$\quad$ Overweight & 1.27 & $0.96,1.68$ & 0.10 \\
$\quad$ Normal & Ref & & \\
$\quad$ Underweight & 0.97 & $0.69,1.37$ & 0.88 \\
$\quad$ Severely wasted & 1.01 & $0.73,1.38$ & 0.97 \\
\hline
\end{tabular}

${ }^{*}$ p-Value from multivariable Cox proportional hazard model.

${ }^{\dagger}$ Nutritional status defined as severely wasted if $\mathrm{BMl}<1$ st percentile, underweight if BMI 1st-5th percentile, overweight if BMI 85-95th percentile, obese if $\mathrm{BMI}>$ 95th percentile, and normal if otherwise.

when the entire cohort was analyzed together. The explanation for this apparent difference in risk conferred by abnormal nutrition is not entirely clear.

Published studies directly evaluating differences in risk factors between patients with $\mathrm{CM}$ and CHD are lacking. A recent pediatric HTx study analysis assessed post-HTx outcomes in each of these populations and demonstrated that risk profiles vary based on heart disease etiology $(8,9)$. Our study provides additional evidence that risk factors are modified by disease etiology and an individualized approach to risk factor assessment based on diagnosis may be warranted.

There are limited and conflicting data regarding the effect of nutrition on pediatric HTx outcomes (2-5). Single center studies have concluded that BMI $<5$ th percentile (2) and
Table 4. Odds of non-survival to transplant based on pre-transplant nutrition in patients with $\mathrm{CM}(\mathrm{N}=1662)$ and $\mathrm{CHD}(\mathrm{N}=975)$

\begin{tabular}{|c|c|c|c|}
\hline Characteristics & $\mathrm{AOR}$ & $95 \% \mathrm{Cl}$ & $p$-Value* \\
\hline \multicolumn{4}{|l|}{ Cardiomyopathy } \\
\hline Nutritional status at & & & 0.01 \\
\hline Obese & 1.96 & $1.24,3.09$ & 0.004 \\
\hline Overweight & 1.56 & $0.91,2.68$ & 0.10 \\
\hline Normal & Ref & & \\
\hline Underweight & 1.03 & $0.52,2.02$ & 0.94 \\
\hline Severely wasted & 2.17 & $1.28,3.68$ & 0.004 \\
\hline \multicolumn{4}{|l|}{ Congenital heart disease } \\
\hline Nutritional status at & & & 0.89 \\
\hline Obese & 0.89 & $0.49,1.64$ & 0.72 \\
\hline Overweight & 0.79 & $0.41,1.51$ & 0.47 \\
\hline Normal & Ref & & \\
\hline Underweight & 0.77 & $0.39,1.53$ & 0.65 \\
\hline Severely wasted & 0.88 & $0.51,1.52$ & 0.45 \\
\hline
\end{tabular}

${ }^{*} \mathrm{p}$-Value from multivariable logistic regression.

${ }^{\dagger}$ Nutritional status defined as severely wasted if $\mathrm{BMI}<1$ st percentile, underweight if BMI 1st-5th percentile, overweight if BMI 85-95th percentile, obese if $\mathrm{BMI}>$ 95th percentile, and normal if otherwise.

Table 5. Hazard ratios of non-survival at one and five yr post-transplant based on pre-transplant nutrition in patients with $\mathrm{CM}(\mathrm{N}=1490)$ and $\mathrm{CHD}$ $(\mathrm{N}=800)$

\begin{tabular}{|c|c|c|c|}
\hline Characteristics & AHR & $95 \% \mathrm{Cl}$ & $\mathrm{p}$-Value* \\
\hline \multicolumn{4}{|l|}{ Cardiomyopathy } \\
\hline $\begin{array}{c}\text { One-yr non-survival based on } \\
\text { nutritional status at listing }\end{array}$ & & & 0.62 \\
\hline Obese & 1.32 & $0.76,2.31$ & 0.32 \\
\hline Overweight & 1.44 & $0.81,2.56$ & 0.22 \\
\hline Normal & Ref & & \\
\hline Underweight & 1.29 & $0.61,2.71$ & 0.51 \\
\hline Severely wasted & 1.44 & $0.73,2.84$ & 0.29 \\
\hline $\begin{array}{l}\text { Five-yr non-survival based on } \\
\text { nutritional status at listing }\end{array}$ & & & 0.51 \\
\hline Obese & 1.22 & $0.87,1.71$ & 0.25 \\
\hline Overweight & 1.32 & $0.92,1.89$ & 0.13 \\
\hline Normal & Ref & & \\
\hline Underweight & 1.08 & $0.66,1.77$ & 0.77 \\
\hline Severely wasted & 1.22 & $0.77,1.94$ & 0.39 \\
\hline \multicolumn{4}{|l|}{ Congenital heart disease } \\
\hline $\begin{array}{c}\text { One-yr non-survival based on } \\
\text { nutritional status at listing }\end{array}$ & & & 0.97 \\
\hline Obese & 1.09 & $0.57,2.07$ & 0.79 \\
\hline Overweight & 1.05 & $0.54,2.06$ & 0.88 \\
\hline Normal & Ref & & \\
\hline Underweight & 0.79 & $0.38,1.64$ & 0.52 \\
\hline Severely wasted & 0.99 & $0.54,1.84$ & 0.99 \\
\hline $\begin{array}{l}\text { Five-yr non-survival based on } \\
\text { nutritional status at listing }\end{array}$ & & & 0.98 \\
\hline Obese & 0.89 & $0.54,1.48$ & 0.66 \\
\hline Overweight & 1.03 & $0.62,1.71$ & 0.91 \\
\hline Normal & Ref & & \\
\hline Underweight & 0.89 & $0.54,1.46$ & 0.65 \\
\hline Severely wasted & 0.95 & $0.60,1.49$ & 0.81 \\
\hline
\end{tabular}

${ }^{*}$ p-Value from multivariable Cox proportional hazard model.

${ }^{\dagger}$ Nutritional status defined as severely wasted if $\mathrm{BMI}<1$ st percentile, underweight if BMI 1st-5th percentile, overweight if BMI 85-95th percentile, obese if $\mathrm{BMI}>$ 95th percentile, and normal if otherwise. 
obesity (3) are associated with decreased postHTx survival. These findings are consistent with studies among adult HTx recipients, where preHTx cachexia and obesity have been associated with worse post-HTx outcomes $(6,7)$. In contrast to these findings, an analysis of the International Society for Heart and Lung Transplantation database demonstrated no correlation between nutritional status and post-HTx outcomes in children (4). Nutritional status has also been shown to influence waitlist outcomes for children $<$ two yr of age, with both moderate/severe wasting and elevated weight-to-height ratio being associated with an increased risk of waitlist mortality (1). None of these previous studies assessed the impact of nutrition stratified by diagnosis, and our unique finding that the risk imparted by abnormal nutrition is modified by pre-HTx diagnosis has not previously been reported.

There are several potential explanations for the varying impact of nutrition on waitlist mortality based on pre-HTx diagnosis. Patients with $\mathrm{CHD}$ in this cohort experienced a higher waitlist mortality $(18 \%)$ compared with patients with CM $(10 \%)$, which is consistent with prior reports that CHD is an independent risk factor for waitlist death (10). The factors contributing to this increased waitlist mortality in CHD may outweigh any added risk conferred by abnormal nutrition. Additionally, the indications for HTx vary between patients with CM and CHD. The $\mathrm{CM}$ group in our study consisted primarily of patients with dilated CM, in whom systolic dysfunction is the most likely indication for HTx, and may in fact predispose these patients to malnutrition (11-13). While systolic dysfunction may also prompt consideration of HTx in patients with CHD, the indications for HTx in this group are much more heterogeneous. The most common indications for HTx in patients with CHD outside of the newborn period are failed single ventricle palliation and those with a systemic right ventricle $(14,15)$. Heart failure in these groups may not be manifest as isolated systolic dysfunction and instead may be secondary to pulmonary hypertension, arrhythmias, elevated venous pressures, or significant atrioventricular valve regurgitation. Piran and colleagues reported higher rates of cyanosis and arrhythmias in adult patients with CHD and symptomatic heart failure (16). This represents a distinctly different pathophysiology than systolic dysfunction, which may not be as susceptible to nutritional effects. Additionally, the etiology of wasting may be different between patients with $\mathrm{CHD}$ and CM, and there is evidence that cyanosis and pulmonary hypertension may play an important role in the development of growth failure in patients with CHD (17).

Optimizing nutritional status may play a role in improving survival to HTx in patients with $\mathrm{CM}$; however, the best way to achieve this is unknown. Adequate caloric intake in patients with significant heart failure may be difficult to attain (18), and poor growth has been demonstrated, despite aggressive enteral nutritional support (19). Significant heart failure may lead to wasting and preclude an anabolic state regardless of nutritional intervention $(1,19)$. Aggressive support with enteral and/or parenteral nutrition may be warranted, and early involvement of a dietician as part of the multidisciplinary team may be beneficial. For patients with $\mathrm{CM}$ and growth failure refractory to medical intervention, consideration of VAD placement or earlier listing for HTx may improve waitlist survival (1). Further research is required to outline the optimal support strategies for these patients and to determine whether improvement in pre-HTx BMI mitigates the risk of waitlist death.

The secondary analyses performed suggest that era may have impacted the role of nutrition in HTx outcomes. The more contemporary cohort includes a time when pediatric VAD use was increasing; however, the inclusion of VAD requirement in the multivariable analysis makes it unlikely that this change in practice influenced this result. Regardless of era, severe wasting remained an independent risk factor for waitlist mortality in patients with CM, but not CHD. Obesity, however, was not a risk factor for waitlist mortality in the more recent era. The significance of this change is unclear; era-based practice change may reduce the influence of obesity on poor outcome in these patients. Alternatively, significant analytic power was lost when assessing the more contemporary cohort, which could also explain the loss of obesity as an independent risk factor. Further assessment of obesity as a risk factor is warranted in future analyses. Additionally, these data do not support a strategy to use significantly elevated BMI as a contraindication to listing for HTx given that no significant differences were found in waitlist or post-HTx mortality. However, this analysis was limited by small patient numbers and therefore warrants further study.

\section{Limitations}

There are several limitations to this study. The OPTN database precludes a detailed analysis due to lack of data granularity. Also, data may be missing or erroneous, and it is not 
possible to retrospectively assure accuracy of the data provided, despite attempts to limit inclusion of erroneous data. Because exact ages are unavailable in the OPTN data, BMI percentiles were calculated at the half-year mark for each patient. The half-year mark was chosen in an attempt to minimize error, but some degree of error was unavoidable. Also, BMI does not account for fluid overload. This could lead to misclassification of patients with significant edema.

\section{Conclusion}

Severe wasting and obesity are independent risk factors for waitlist mortality in pediatric patients with CM, but not those with CHD. Further investigation is required to determine whether optimizing pre-HTx nutritional status can improve HTx outcomes. Abnormal pre-HTx nutritional status should not influence the decision to list for HTx, given equivalent post-HTx outcomes in all groups. Future studies assessing risk factors should consider stratifying analyses based on diagnoses to avoid overlooking potentially important findings.

\section{Disclosure}

This work was supported in part by Health Resources and Services Administration contract 234-2005-37011C. The content is the responsibility of the authors alone and does not necessarily reflect the views or policies of the Department of Health and Human Services, nor does mention of trade names, commercial products, or organizations imply endorsement by the U.S. Government. None of the authors has a financial relationship with a commercial entity that has an interest in the subject of the presented manuscript or other conflicts of interest to disclose.

\section{Authors' contributions}

Justin Godown: Participated in concept/design, data interpretation, drafting of the article; Janet E. Donohue: Participated in database management, data collection, concept/ design, critical revision of the article; Sunkyung Yu: Participated in statistical analysis, concept/design, critical revision of the article; Joshua M. Friedland-Little, Robert J. Gajarski: Participated in critical revision of the article; Kurt R. Schumacher: Participated in concept/design, data interpretation, drafting the article, critical revision of the article.

\section{References}

1. Godown J, Friedland-Little JM, Gajarski RJ, Yu S, DonOHUE JE, Schumacher KR. Abnormal nutrition affects waitlist mortality in infants awaiting heart transplant. J Heart Lung Transplant 2014: 33: 235-240.

2. Rossano JW, Grenier MA, Dreyer WJ, et al. Effect of body mass index on outcome in pediatric heart transplant patients. J Heart Lung Transplant 2007: 26: 718-723.

3. Kaufman BD, Nagle ML, Levine SR, et al. Too fat or too thin? Body habitus assessment in children listed for heart transplant and impact on outcome. J Heart Lung Transplant 2008: 27: 508-513.

4. Kaufman BD, Chuai S, Dobbels F, Shaddy RE. Wasting or obesity at time of transplant does not predict pediatric heart transplant outcomes: Analysis of ISHLT pediatric heart transplant registry. J Heart Lung Transplant 2009: 28: 1273-1278.

5. Rossano JW, Smith EO, Denfield SW. Body habitus and survival in pediatric heart transplant patients. J Heart Lung Transplant 2008: 27: 1187-1188.

6. Grady KL, White-Williams C, Naftel D, et al. Are preoperative obesity and cachexia risk factors for post heart transplant morbidity and mortality: A multi-institutional study of preoperative weight-height indices. Cardiac Transplant Research Database (CTRD) Group. J Heart Lung Transplant 1999: 18: 750-763.

7. Lietz K, John R, Burke EA, et al. Pretransplant cachexia and morbid obesity are predictors of increased mortality after heart transplantation. Transplantation 2001: 72: 277-283.

8. Schumacher KR, Naftel D, Tresler M, et al. Predicting 1year survival in pediatric heart transplant candidates with congenital heart disease: An analysis of the PHTS database. J Heart Lung Transplant 2012: 31: S112.

9. Schumacher KR, Naftel D, Tresler M, et al. Predicting 1year survival in pediatric heart transplant candidates with cardiomyopathy: An analysis of the PHTS database. J Heart Lung Transplant 2012: 31: S17.

10. Almond CS, Thiagarajan RR, Piercey GE, et al. Waiting list mortality among children listed for heart transplantation in the United States. Circulation 2009: 119: 717-727.

11. Miller Tl, Neri D, Extein J, Somarriba G, Strickman-Stein N. Nutrition in pediatric cardiomyopathy. Prog Pediatr Cardiol 2007: 24: 59-71.

12. Webb JG, Kiess MC, Chan-Yan CC. Malnutrition and the heart. CMAJ 1986: 135: 753-758.

13. Anker SD, Sharma R. The syndrome of cardiac cachexia. Int J Cardiol 2002: 85: 51-66.

14. Lamour JM, Kanter KR, Naftel DC, et al. The effect of age, diagnosis, and previous surgery in children and adults undergoing heart transplantation for congenital heart disease. J Am Coll Cardiol 2009: 54: 160-165.

15. Sian Pincott E, Burch M. Indications for heart transplantation in congenital heart disease. Curr Cardiol Rev 2011: 7: 5158.

16. Piran S, Veldtman G, Siu S, Webb GD, Liu PP. Heart failure and ventricular dysfunction in patients with single or systemic right ventricles. Circulation 2002: 105: 1189-1194.

17. Varan B, Tokel K, Yilmaz G. Malnutrition and growth failure in cyanotic and acyanotic congenital heart disease with and without pulmonary hypertension. Arch Dis Child 1999: 81: 4952 .

18. Aquilani R, Opasich C, Verri M, et al. Is nutritional intake adequate in chronic heart failure patients? J Am Coll Cardiol 2003: 42: 1218-1223.

19. Bannister L, Manlhiot C, Pollock-BarZiv S, Stone T, McCrindle BW, Dipchand AI. Anthropometric growth and utilization of enteral feeding support in pediatric heart transplant recipients. Pediatr Transplant 2010: 14: 879-886. 